\title{
PENGARUH KETERSEDIAAN SARANA TERHADAP PRAKTIK CUCI TANGAN PAKAI SABUN (CTPS) SISWA SEKOLAH DASAR
}

\section{The Influence of Facilities Availability on Soap Use of Washes In elementary school students}

\author{
Sapriana, Maryam, Ros Arianty \\ Poltekkes Kemenkes Palu \\ (sapriana25@gmail.com)
}

\begin{abstract}
ABSTRAK
Cuci tangan dengan sabun pada air mengalir adalah langkah sederhana dan efektif untuk mencegah penularan penyakit fecal-oral dan penyakit menular lainnya pada anak usia sekolah. Tujuan penelitian untuk mengetahui pengaruh ketersediaan sarana cuci tangan terhadap praktik cuci tangan pakai sabun di sekolah dasar. Penelitian kuasi eksperimen the nonrandomized pretest posttest control group design. Populasi penelitian adalah siswa SDIT Hidayatullah Palu dan SDN 08 Kecamatan Tanantovea Kabupaten Donggala. Jumlah sampel 60 orang terdiri dari 49 orang pada kelompok perlakuan dan 11 orang pada kelompok kontrol. Data dikumpulkan dengan cara menilai pre-posttest. Instrumen penelitian berupa kuesioner dan angket. Variabel bebas adalah sarana cuci tangan dan sabun sedangkan variabel terikatnya adalah praktik cuci tangan pakai sabun pada air mengalir. Data dianalisis untuk melihat pengaruh intervensi terhadap variabel dependen. Hasil penelitian menunjukkan bahwa dari 30,61\% siswa yang sering mencuci tangan saat berada di sekolah meningkat menjadi $67,34 \%$ setelah tersedia sarana CTPS, sebanyak 49 responden $91,83 \%$ mencuci tangan di wastafel, dan sisanya $8,17 \%$ di kamar mandi/wc/kran mesjid. Penggunaan sabun saat cuci tangan mengalami peningkatan dari 30,61\% menjadi $87,75 \%$ dan semuanya menggunakan air mengalir (100\%). Hasil uji Mc Nemar menunjukkan bahwa nilai a $(0,05)>$ p, yang berarti bahwa ada perbedaan praktik CTPS sebelum dan setelah tersedia sarana CTPS pada siswa sekolah dasar. Kesimpulan: ketersediaan sarana CTPS efektif terhadap praktik CTPS di sekolah dasar. Pihak sekolah diharapkan agar dapat menyediakan sabun dan air mengalir secara regular sehingga perilaku CTPS menjadi suatu kebiasaan bagi siswa sekolah dasar.
\end{abstract}

Kata Kunci : cuci tangan pakai sabun, siswa sekolah dasar

\section{ABSTRACT}

Hand Washing With Soap (HWWS) is a simple and effective step to prevent transmission of fecaloral disease and other infectious diseases in school-age children. The research objective was to determine the effect of the availability of hand washing facilities on the practice of washing hands with soap in elementary schools. Quasi-experimental study of the nonrandomized pretest posttest control group design. The study population was students of SDIT Hidayatullah Palu and SDN 08 Tanantovea District, Donggala Regency. The total sample of 60 people consisted of 49 people in the treatment group and 11 people in the control group. Data collected by assessing pre-posttest. Research instruments in the form of questionnaires and questionnaires. The independent variable is a means of washing hands and soap while the dependent variable is the practice of washing hands with soap in running water. Data were analyzed to see the effect of intervention on the dependent variable. The results showed that from $30.61 \%$ of students who frequently washed their hands while at school increased to $67.34 \%$ after HWWS facilities were available, as many as 49 respondents $91.83 \%$ washed their hands in the sink, and the remaining $8.17 \%$ in the bathroom / wc / mosque faucet. The use of soap when washing hands increased from $30.61 \%$ to $87.75 \%$ and all of them used running water (100\%). Mc Nemar test results indicate that the value a (0.05)> $p$, which means that there are differences in HWWS practices before and after the HWWS facility is available in elementary school students. Conclusion: the availability of HWWS facilities is effective against the practice of HWWS in primary schools. The school is expected to be able to provide soap and running water regularly so that CTPS behavior becomes a habit for elementary school students.

Keywords: Hand washing with soap, elementary school students 


\section{PENDAHULUAN}

Cuci Tangan Pakai Sabun (CTPS) pada air mengalir merupakan salah satu bagian dalam Perilaku hidup bersih dan sehat (PHBS). Cuci tangan dengan sabun pada air mengalir adalah langkah sederhana dan efektif untuk mencegah penularan penyakit fecal-oral dan penyakit menular lainnya pada anak usia sekolah ${ }^{(1)}$. Mencuci tangan dengan sabun dan memotong kuku setiap minggu secara signifikan menurunkan tingkat infeksi ulang parasit usus ${ }^{(2)}$. Perilaku ini mencegah penularan penyakit $\operatorname{diare}^{(3)}$, kolera, disentri, typus, cacingan, penyakit kulit, hepatitis A, flu burung dan coronavirus.

$\begin{array}{clr}\text { Program } & \text { CTPS berbasis } & \text { sekolah } \\ \text { meningkatkan } & \text { pengetahuan dan perilaku }\end{array}$ kebersihan siswa sekolah serta mengurangi ketidakhadiran karena diare ${ }^{(4)}$. Mencuci tangan adalah aktivitas harian paling penting untuk menjaga infeksi mikroba. Anak-anak sekolah cenderung memperoleh sebagian besar infeksi dengan tidak mengikuti protokol sering mencuci tangan yang sering menyebabkan penyakit dan ketidakhadiran di sekolah. Tangan anak-anak sekolah sering ditemukan telah terkontaminasi dan langkah-langkah untuk menanamkan kebiasaan mencuci tangan dengan sabun sangat penting. Penelitian Otsuka (2019) menunjukkan bahwa masalah air, sanitasi, dan kebersihan merupakan faktor risiko untuk kurang gizi dan diare di Indonesia ${ }^{(5)}$. Proporsi perilaku cuci tangan dengan benar pada penduduk umur $>=10$ tahun secara nasional pada tahun 2007 sebesar $23,2 \%$, tahun 2013 sebesar $47 \%{ }^{(6)}$ dan tahun 2018 sebesar $49,8 \%^{(7)}$.

Sulawesi Tengah merupakan salah satu propinsi dengan proporsi perilaku cuci dibawah angka nasional dan proporsinya mengalami penurunan pada tahun 2018, lebih rendah dari tahun sebelumnya (tahun 2013 sebesar 44,3\%). Secara global, tantangan mencuci tangan dengan sabun masih ada meskipun pentingnya CTPS telah diperlihatkan sebelumnya ${ }^{(8)}$. Tujuan penelitian ini untuk mengetahui pengaruh ketersediaan sarana terhadap praktik cuci tangan pakai sabun di sekolah dasar.

\section{METODE PENELITIAN}

Penelitian menggunakan kuasi eksperimen the nonrandomized pretest posttest control group design. Populasi penelitian adalah siswa SDIT Hidayatullah Palu dan SDN 08 Kecamatan Tanantovea Kabupaten Donggala. Jumlah sampel 60 orang terdiri dari 49 orang pada kelompok perlakuan dan 11 orang pada kelompok kontrol Data dikumpulkan dengan cara menilai pre-post test. Adapun instrumen penelitian berupa kuesioner dan angket. Variabel bebas adalah sarana cuci tangan dan sabun sedangkan variabel terikatnya adalah praktik cuci tangan pakai sabun. Selanjutnya data dianalisis untuk melihat pengaruh intervensi terhadap variabel dependen.

HASIL

Hasil penelitian menunjukkan bahwa dari $30,61 \%$ siswa yang sering mencuci tangan saat berada di sekolah meningkat menjadi $67,34 \%$ setelah tersedia sarana CTPS. Dari 49 responden 91,83\% mencuci tangan di wastafel, dan sisanya $8,17 \%$ di kamar mandi/wc/kran mesjid. penggunaan sabun saat cuci tangan mengalami peningkatan dari $30,61 \%$ menjadi $87,75 \%$ dan $100 \%$ menggunakan air mengalir. Hasil uji $M c$ Nemar menunjukkan bahwa nilai a $(0,05)>$ p, yang berarti bahwa ada perbedaan praktik CTPS sebelum dan setelah tersedia sarana CTPS pada siswa sekolah dasar atau dengan kata lain bahwa ketersediaan sarana CTPS efektif terhadap praktik CTPS siswa sekolah dasar sebagaimana pada tabel berikut:

Tabel 1. Pengaruh Ketersediaan Sarana CTPS Terhadap Praktik CTPS

\begin{tabular}{cccc}
\hline \multirow{2}{*}{$\begin{array}{c}\text { CTPS } \\
\text { sebelum } \\
\text { ada sarana }\end{array}$} & \multicolumn{2}{c}{$\begin{array}{c}\text { Cuci Tangan Pakai } \\
\text { Sabun (CTPS) } \\
\text { Setelah ada sarana }\end{array}$} & \multirow{2}{*}{ Sig. } \\
\cline { 2 - 3 } & Ya & Tidak & \\
\hline Ya & 13 & 1 & \multirow{2}{*}{0,000} \\
Tidak & 30 & 5 & \\
\hline Jumlah & 43 & 6 & \\
\hline
\end{tabular}

Sumber : Data Primer, 2017

Berdasarkan Tabel 1 dapat diketahui bahwa dari 43 responden yang melakukan CTPS setelah ada sarana, 30 responden atau $87 \%$ adalah responden yang sebelum tersedia sarana tidak mencuci tangan pakai sabun. Sebaliknya dari 6 responden yang tidak melakukan CTPS setelah ada sarana 1 orang $(16,67 \%)$ diantaranya adalah 
responden yang mengalami perubahan yang tidak diharapkan, sebelum ada sarana melakukan CTPS kemudian setelah ada sarana menjadi tidak melakukan CTPS. Hasil analisis dengan Mc Nemar Test, diperoleh $p$ value 0,000 yang berarti bahwa ada pengaruh ketersediaan sarana CTPS terhadap praktik CTPS siswa.

\section{PEMBAHASAN}

SDIT Hidayatullah adalah salah satu sekolah dasar swasta di Kota Palu dan SDN 08 Tanantovea adalah sekolah dasar negeri yang berada di Kabupaten Donggala. Setelah ada sarana dari 43 responden yang melakukan CTPS sebanyak $87 \%$ responden mengalami perubahan dari tidak melakukan CTPS menjadi melakukan CTPS. Sebaliknya $16,67 \%$ mengalami perubahan yang tidak diharapkan, sebelum ada sarana melakukan CTPS namun setelah ada sarana menjadi tidak melakukan CTPS. Uji Mc Nemar Test menunjukkan $p$ value 0,000 yang berarti bahwa ada pengaruh ketersediaan sarana CTPS terhadap praktik CTPS siswa atau ketersediaan sarana CTPS efektif terhadap praktik CTPS siswa. Mencuci tangan dengan sabun adalah perilaku kesehatan preventif yang penting, namun mempromosikan perilaku ini terbukti sulit ${ }^{(9)}$. Teknik mencuci tangan yang benar dan CTPS pada waktu yang tepat dapat mengurangi kontaminasi feses. Selain itu, penting bahwa pendidikan mencuci tangan berbasis kelas dan gender dipertimbangkan dalam pendidikan sekolah dasar ${ }^{(8)}$. Sangat sedikit penelitian yang mengevaluasi intervensi cuci tangan yang menargetkan anak-anak. Sangat masuk akal bahwa intervensi yang berhasil mengubah praktik cuci tangan anak-anak akan menyebabkan dampak kesehatan yang signifikan mengingat banyak dari beban penyakit yang disebabkan terkonsentrasi pada kelompok usia tersebut. Kurangnya bukti saat ini di bidang ini, bagaimanapun, tidak mengizinkan rekomendasi yang dibuat untuk rute yang paling efektif untuk meningkatkan praktik cuci tangan dengan sabun di antara anak-anak di di negara-negara berpenghasilan rendah dan menengah ${ }^{(10)}$.

Penelitian Otsuka et.al menunjukkan di dua sekolah dasar dengan 169 anak-anak di daerah padat penduduk di Bandung, Indonesia. Survei ini melibatkan observasi cuci tangan menggunakan daftar periksa, pengambilan sampel bakteri tangan, dan kuesioner. Sebagian besar anak-anak $(98,7 \%)$ memiliki kontaminasi tinja. Anak perempuan memiliki Escherichia coli lebih sedikit daripada anak laki-laki $(p<0,05)$. Kemampuan dalam teknik mencuci tangan, CTPS dan pengetahuan dan kesadaran tentang air, sanitasi dan hygene masih rendah. Jumlah Escherichia coli berkorelasi negatif dengan teknik cuci tangan $(r=-0,171, p<0,05)$, CTPS $(r=$ $-0,225, \mathrm{P}<0,01)$ dan indeks WASH $(\mathrm{r}=-0,205, \mathrm{P}$ $<0,05)^{(8)}$.

Penelitian Duijster et all (2017) menunjukkan bahwa Program Fit for School (FIT) mengintegrasikan intervensi kesehatan, air, sanitasi dan kebersihan sekolah yang dilaksanakan oleh Kementerian Pendidikan di empat negara Asia Tenggara. Studi ini menemukan bahwa program FIT secara signifikan berkontribusi pada pencegahan karies gigi pada anak-anak. Studi ini menggambarkan tantangan, pembelajaran dan lebih lagi pentingnya melakukan penelitian implementasi kehidupan nyata untuk mengevaluasi program kesehatan untuk mengubah pengaturan sekolah menjadi lingkungan belajar yang sehat untuk anak-anak. Penelitian ini adalah uji coba terkontrol non-acak terkelompok dengan periode tindak lanjut dua tahun. Kelompok intervensi terdiri dari anak-anak yang menghadiri sekolah dasar negeri yang melaksanakan program FIT, termasuk kelompok harian mencuci tangan dengan sabun dan menyikat gigi dengan pasta gigi berfluoride, obat cacing berbasis sekolah dua tahunan; serta pembangunan fasilitas cuci tangan kelompok. Sekolah kontrol menerapkan kurikulum pendidikan kesehatan reguler pemerintah dan cacing dua tahunan. Di setiap sekolah, dipilih secara acak siswa kelas enam hingga tujuh tahun yang acak. Data tentang infeksi parasitologis, pengukuran antropometrik, karies gigi, infeksi odontogenik dan karakteristik sosiodemografi dikumpulkan pada awal dan pada tindak lanjut (24 bulan kemudian). Sebanyak 1847 anak-anak berpartisipasi dalam survei dasar. Dari jumlah tersebut, 1.499 anak bersedia untuk pemeriksaan tindak lanjut masing-masing 478, 486 dan 535 anak di Kamboja, Indonesia dan Laos. Di ketiga negara, anak-anak di sekolah intervensi memiliki peningkatan yang lebih 
rendah dalam jumlah gigi permanen yang membusuk, hilang dan terisi antara garis dasar dan tindak lanjut, dibandingkan dengan anakanak di sekolah kontrol. Fraksi preventif rata-rata $24 \%$. Prevalensi infeksi cacing yang ditularkan melalui tanah yang secara tak terduga rendah pada awal, prevalensi ketipisan dan prevalensi infeksi odontogenik tidak berbeda secara signifikan antara awal dan tindak lanjut, maupun antara sekolah intervensi dan kontrol ${ }^{(11)}$.

Banyak orang tidak memiliki fasilitas cuci tangan yang ditentukan, tetapi bahkan di antara mereka yang memiliki akses, CPTS kurang dipraktikkan. Orang-orang dengan akses ke fasilitas cuci tangan yang ditunjuk sekitar dua kali lebih mungkin untuk mencuci tangan mereka dengan sabun setelah kontak feses yang potensial dengan orang-orang yang tidak memiliki fasilitas $^{(12)}$.

Penelitian Grover et all menunjukkan bahwa peran pengaruh sosial dalam mencuci tangan dengan sabun di lingkungan sekolah dasar. Menggunakan data yang dikumpulkan melalui kamera video rahasia di luar jamban sekolah, menilai dampak pengaruh sosial yang didefinisikan sebagai kehadiran orang lain di dekat lokasi cuci tangan setelah keluar dari toilet. terdapat peningkatan 30\% dalam CTPS ketika seseorang hadir, dibandingkan dengan ketika seorang anak sendirian (Rasio Prevalensi 1,30; Interval kepercayaan 95\%: 1,14-1,47, P <0,001). Prevalensi tertinggi CTPS ditemukan ketika anak-anak dan orang dewasa hadir atau ketika anak-anak hanya hadir (64\%). Studi ini menyimpulkan bahwa kehadiran orang lain setelah keluar dari toilet dapat berdampak positif terhadap CTPS di lingkungan sekolah dasar ${ }^{(13)}$.

Di Filipina, evaluasi intervensi air sanitasi dan kebersihan berbasis sekolah. Siswa dan rumah tangga dari empat sekolah yang menerima intervensi WASH dibandingkan dengan empat sekolah kontrol. Pengetahuan tentang waktuwaktu mencuci tangan yang kritis tinggi di semua sekolah, tetapi lebih tinggi di sekolah-sekolah intervensi. Siswa melaporkan tingkat cuci tangan yang lebih tinggi setelah penggunaan toilet $(92 \%$ vs $87 \%$; $R R=1,06 ; p=0,003)$ dan mencuci tangan dengan sabun $(83 \%$ vs $60 \%$; $R R=1,4 ; p<0,001)$ dalam intervensi dibandingkan sekolah kontrol.
Di sekolah intervensi, 89\% siswa secara langsung diamati untuk mencuci tangan setelah menggunakan toilet versus $31 \%$ di sekolah kontrol $(R R=2,84 ; p<0,0001)$. Perbedaan yang diamati dalam mencuci tangan dengan sabun setelah penggunaan toilet ditandai secara khusus ( $65 \%$ vs $10 \%$; RR $=6,5 ; p<0,0001)$. Penggunaan toilet sekolah untuk buang air besar yang dilaporkan (berlawanan dengan penggunaan toilet di tempat lain atau buang air besar sembarangan) lebih tinggi di antara sekolahsekolah intervensi versus sekolah control $(90 \%$ vs $63 \% ; \mathrm{RR}=1,4 ; \mathrm{p}<0,001)$. Pemodelan bertingkat menunjukkan bahwa siswa dari sekolah intervensi melaporkan penurunan odds $10 \mathrm{kali}$ lipat ( $\mathrm{p}<0,001)$ karena tidak adanya diare. Selain temuan berbasis sekolah, cuci tangan yang dilaporkan sendiri pada waktu kritis ditemukan lebih tinggi di antara anggota rumah tangga siswa dari sekolah intervensi. Program WASH berbasis sekolah ini muncul untuk meningkatkan pengetahuan dan perilaku kebersihan siswa sekolah, mengurangi ketidakhadiran karena diare, dan meningkatkan cuci tangan pada saatsaat kritis di antara anggota rumah tangga ${ }^{(4)}$.

Program cuci tangan sekolah harus menciptakan kesadaran akan manfaat mencuci tangan melalui kegiatan pendidikan, meningkatkan kemampuan dan kepercayaan diri anak-anak dalam mencuci tangan di sekolah melalui perbaikan infrastruktur, dan menyoroti normalitas mencuci tangan di sekolah melalui acara dan pembuatan poster ${ }^{(14)}$.

Komunikasi perubahan perilaku untuk meningkatkan mencuci tangan dengan sabun dapat menjadi padat karya dan sumber daya, namun hasil yang berkualitas sulit dicapai. Dalam studi proof-of-concept dikembangkan serangkaian kegiatan untuk mendorong cuci tangan dengan sabun setelah penggunaan toilet di dua sekolah dasar di pedesaan Bangladesh. Pengamatan langsung perilaku pada awal, setelah menyediakan infrastruktur cuci tangan tradisional, dan pada beberapa periode waktu mengikuti dorongan cuci tangan yang ditargetkan (1 hari, 2 minggu, dan 6 minggu). Tidak ada pendidikan mencuci tangan tambahan atau pesan motivasi yang selesai. Cuci tangan dengan sabun di antara anak-anak sekolah rendah pada awal (4\%), meningkat menjadi $68 \%$ sehari setelah 
dorongan selesai dan $74 \%$ pada 2 minggu dan 6 minggu pasca intervensi. Hasil menunjukkan bahwa intervensi berbasis dorongan memiliki potensi untuk meningkatkan cuci tangan dengan sabun di antara anak-anak usia sekolah di Bangladesh ${ }^{(15)}$.

Penelitian Wichaidit et al (2019) menunjukkan bahwa air dan sabun atau air sabun tersedia di 2\% dari kunjungan sekolah sebelum intervensi dan pada $42 \%$ dari kunjungan sekolah setelah intervensi. Sebelum intervensi, pengamatan mencuci tangan dengan air setelah $11 \%$ dari 461 setelah dari toilet; tidak ada yang diamati mencuci tangan dengan sabun / air sabun. Setelah intervensi, pengamatan mencuci tangan $62 \%$ dari 383 setelah penggunaan toilet $(\mathrm{PR}=$ $5,96,95 \% \mathrm{CI}=3,02,11,76)$ dan mencuci tangan dengan sabun/air sabun $26 \%$ setelah penggunaan toilet $^{(16)}$.

Di India, hasil program yang melatih para guru untuk menyampaikan program perubahan perilaku mencuci tangan dengan sabun kepada anak-anak di sekolah dasar. Sepuluh sekolah intervensi dipilih bersama dengan sepuluh sekolah kontrol terdekat, dan sekolah intervensi menerima program "Sekolah Lima" yang mempromosikan cuci tangan dengan sabun menggunakan cerita, permainan, dan lagu interaktif, buku harian perilaku untuk mendorong pembentukan kebiasaan, dan komitmen publik. Cuci tangan dengan sabun diukur menggunakan buku harian stiker sebelum makan dan setelah buang air besar 4 minggu setelah intervensi selesai. Anak-anak melaporkan 15,1\% lebih banyak mencuci tangan dengan sabun pada kesempatan-kesempatan penting $(35,2 \%)$ dibandingkan dengan mereka yang berada dalam kelompok kontrol (20,1\%) (RR: 1,77, CI: $(1,22$, $2,58), p=0,003)$. Tidak ada bukti bahwa mencuci tangan dengan sabun setelah buang air besar lebih tinggi pada kelompok perlakuan daripada kelompok kontrol (RR: 1.18, CI: $(0.88,1.57), \mathrm{p}=$ .265), tetapi ada bukti kuat bahwa mencuci tangan dengan sabun lebih besar dalam pengobatan daripada di kontrol sebelum makan (RR: 2,68, 95\% CI: $(1,43,5,03), \mathrm{p}=0,002)$. Tingkat cuci tangan meningkat baik di rumah (RR: 1,63, CI: 1,14, 2,32), p = 0,007) dan di sekolah (RR: 4,76, 95\% CI: $(1,65,17,9), \mathrm{p}=$ $0,004)$, meskipun dampak pada mencuci tangan dengan sabun pada acara-acara penting di sekolah jauh lebih tinggi daripada di rumah. Mempromosikan mencuci tangan dengan sabun melalui guru di sekolah mungkin merupakan cara yang efektif untuk mencapai perubahan perilaku secara besar-besaran ${ }^{(9)}$. Penelitian Grover (2018) menunjukkan peningkatan perilaku mencuci tangan dapat berkelanjutan hingga 5 bulan setelah intervensi $i^{(17)}$.

\section{KESIMPULAN DAN SARAN}

Dari 49 responden pada kelompok perlakuan, proporsi siswa yang melakukan CTPS sebelum tersedia sarana adalah $30,61 \%$, proporsi siswa yang melakukan CTPS setelah tersedia sarana adalah $87,75 \%$. Ada pengaruh ketersediaan sarana CTPS terhadap praktik CTPS di SDIT Hidayatullah Palu atau dengan kata lain bahwa ketersediaan sarana CTPS efektif terhadap praktik CTPS di SDIT Hidayatullah Palu. Kepada pihak sekolah diharapkan agar dapat menjaga kesinambungan ketersediaan handsoap dan air mengalir sehingga perilaku CTPS menjadi kebiasaan siswa.

\section{UCAPAN TERIMA KASIH}

Terima kasih disampaikan kepada Bapak Nasrul, SKM, M.Kes selaku Direktur Poltekkes kemenkes Palu, Bapak Dedi Kurniawan, S.Sos.I selaku Kepala SDIT Hidayatullah Palu beserta staf, Bapak Mahsyar selaku Kepala SDN 08 Tanantovea Kabupaten Donggala beserta staf atas kerjasamanya selama pelaksanaan penelitian, para murid, para guru SDIT Hidayatullah Palu dan SDN 08, yang telah berpartisipasi sebagi enumerator dan responden penelitian.

\section{DAFTAR PUSTAKA}

1. Xuan LTT, Hoat LN. Handwashing among schoolchildren in an ethnically diverse population in northern rural Vietnam. Glob Health Action. 2013 Jan;6:1-8.

2. Mahmud MA, Spigt M, Bezabih AM, Pavon IL, Dinant G-J, Velasco RB. Efficacy of Handwashing with Soap and Nail Clipping on Intestinal Parasitic Infections in School-Aged Children: A Factorial Cluster Randomized Controlled Trial. PLoS Med. 2015 Jun;12(6):e1001837; discussion e1001837. 
3. Slekiene J, Mosler H-J. Does depression moderate handwashing in children? BMC Public Health. 2017 Aug;18(1):82.

4. Vally H, McMichael C, Doherty C, Li X, Guevarra G, Tobias P. The Impact of a School-Based Water, Sanitation and Hygiene Intervention on Knowledge, Practices, and Diarrhoea Rates in the Philippines. Int J Environ Res Public Health. 2019 Oct;16(21).

5. Otsuka Y, Agestika L, Widyarani, Sintawardani N, Yamauchi T. Risk Factors for Undernutrition and Diarrhea Prevalence in an Urban Slum in Indonesia: Focus on Water, Sanitation, and Hygiene. Am J Trop Med Hyg. 2019 Mar;100(3):727-32.

6. RI KK. Riset Kesehatan Dasar [Basic Health Research] [Internet]. Vol. 2014. Jakarta: Balitbangkes MoH; 2013. Available from: http://depkes.go.id/downloads/riskesdas2013/ Hasil Riskesdas 2013.pdf

7. Health Research and Development Body Ministry of Health Republic of Indonesia. Basic Health Research Report of Indonesia Year 2018 (Laporan Nasional Riskesdas 2018). Riskesdas 2018. Jakarta; 2018.

8. Otsuka Y, Agestika L, Harada H, Sriwuryandari L, Sintawardani N, Yamauchi T. Comprehensive assessment of handwashing and faecal contamination among elementary school children in an urban slum of Indonesia. Trop Med Int Health. 2019 Aug;24(8):954-61.

9. Tidwell JB, Gopalakrishnan A, Unni A, Sheth E, Daryanani A, Singh S, et al. Impact of a teacher-led school handwashing program on children's handwashing with soap at school and home in Bihar, India. PLoS One. 2020;15(2):e0229655.

10. Watson JA, Ensink JHJ, Ramos M, Benelli P, Holdsworth E, Dreibelbis R, et al. Does targeting children with hygiene promotion messages work? The effect of handwashing promotion targeted at children, on diarrhoea, soil-transmitted helminth infections and behaviour change, in low- and middle-income countries. Trop Med Int Health. 2017
May;22(5):526-38.

11. Duijster D, Monse B, Dimaisip-Nabuab J, Djuharnoko P, Heinrich-Weltzien R, Hobdell $\mathrm{M}$, et al. "Fit for school" - a school-based water, sanitation and hygiene programme to improve child health: Results from a longitudinal study in Cambodia, Indonesia and Lao PDR. BMC Public Health. 2017 Apr;17(1):302.

12. Wolf J, Johnston R, Freeman MC, Ram PK, Slaymaker T, Laurenz E, et al. Handwashing with soap after potential faecal contact: global, regional and country estimates. Int $\mathrm{J}$ Epidemiol. 2019 Aug;48(4):1204-18.

13. Grover E, Hossain MK, Uddin S, Venkatesh M, Ram PK, Dreibelbis R. Social Influence on Handwashing with Soap: Results from a Cluster Randomized Controlled Trial in Bangladesh. Am J Trop Med Hyg. 2018 Oct;99(4):934-6.

14. Seimetz E, Slekiene J, Friedrich MND, Mosler H-J. Identifying behavioural determinants for interventions to increase handwashing practices among primary school children in rural Burundi and urban Zimbabwe. BMC Res Notes. 2017 Jul;10(1):280.

15. Dreibelbis R, Kroeger A, Hossain K, Venkatesh M, Ram PK. Behavior Change without Behavior Change Communication: Nudging Handwashing among Primary School Students in Bangladesh. Int J Environ Res Public Health. 2016 Jan;13(1).

16. Wichaidit W, Steinacher R, Okal JA, Whinnery J, Null C, Kordas K, et al. Effect of an equipment-behavior change intervention on handwashing behavior among primary school children in Kenya: the Povu Poa school pilot study. BMC Public Health. 2019 May;19(1):647.

17. Grover E, Hossain MK, Uddin S, Venkatesh M, Ram PK, Dreibelbis R. Comparing the behavioural impact of a nudge-based handwashing intervention to high-intensity hygiene education: a cluster-randomised trial in rural Bangladesh. Trop Med Int Health. 2018 Jan;23(1):10-25. 